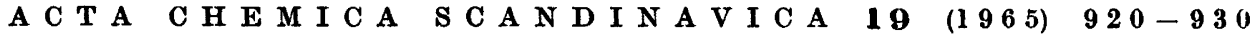

\title{
Studies of Cyclic Acetal and Ketal Isomers of Glycerol
}

\author{
GUNNAR AKSNES, PER ALBRIKTSEN and PAUL JUVVIK
}

Chemical Institute, University of Bergen, Bergen, Norway

\begin{abstract}
The present paper reports the gas chromatographic separation of four acetal isomers from the reaction between glycerol and acetaldehyde. From studies of their infrared spectra, refractive indexes, and densities, the isomers are identified as cis and trans 4-hydroxymethyl-2-methyl-1,3-dioxolane, and cis and trans 5-hydroxy-2methyl-1,3-dioxane. The equilibrium ratios of the isomers are studied at four different temperatures, and from these ratios the enthalpy difference between the equilibrium mixture of 1,3-dioxolane isomers and the equilibrium mixture of 1,3-dioxane isomers is calculated to be $-7.0 \pm 0.5 \mathrm{kcal}$. The rates of isomerisation of the pure isomers are studied with and without added catalyst.

A few percent yield of the cyclic ketal isomer, 5-hydroxy-2,2 dimethyl-1,3-dioxane, has been obtained by isomerisation of the five-membered isomer, 4-hydroxymethyl-2,2-dimethyl-1,3-dioxolane at temperatures below $0^{\circ} \mathrm{C}$.
\end{abstract}

$\mathbf{H}^{2}$ arnitzky and Menschutkin ${ }^{1}$ a century ago reported the formation of a cyclic acetal from glycerol and acetaldehyde. This condensation reaction was later studied by Nef. ${ }^{2}$ Hibbert et al. ${ }^{3,4}$ succeeded in isolating, from the condensation product, two benzoates, which upon alkaline hydrolysis gave 4-hydroxymethyl-2-methyl-1,3-dioxolane (I) and 5-hydroxy-2-methyl-1,3dioxane (II):

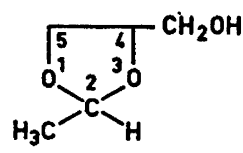

(I)<smiles></smiles>

(II)

From the tosylate derivatives of (I) Triggle and Belleau ${ }^{5}$ isolated the cis and trans isomers, but no physical data except the boiling points were reported.

In contrast to cyclic ketals, five-membered acetals are reported to be less stable than six-membered ones. ${ }^{6}$ In the case of ketals, the lower stability of 
the 1,3-dioxane ring as compared with the 1,3-dioxolane ring is believed to be due to an axial repulsion between one of the alkyl groups in the 2-position of the 1,3-dioxane ring and the axial hydrogen atoms in the 4- and 6-positions. ${ }^{6}$ In six-membered acetals, the 2-hydrogen atom instead of an alkyl group can be in axial opposition to the axial hydrogen atoms of the 4- and 6-positions, and give rise to only a slight repulsion.

The present paper reports the gas chromatographic separation of the cis and trans pairs of the cyclic glycerol acetals (I) and (II). The configurations of the isomers are discussed on the background of their infrared spectra, refractive indexes and densities. From determination of the isomer ratio at various temperatures, the enthalpy differences between the pair of 1,3-dioxolane isomers and the pair of 1,3-dioxane isomers have been calculated. The rates of isomerisation of the pure isomers with and without added catalyst have also been studied.

The 1,3-dioxolane and 1,3-dioxane derivatives formed from acetone and glycerol have been synthetised and studied in some detail.

\section{EXPERIMENTAL}

The isomer mixture of the cyclic acetals (I) and (II) was synthetised according to the method of Hibbert et al. ${ }^{4}$

The cyclic ketal, 4-hydroxymethyl-2,2-dimethyl-1,3-dioxolane, was synthetised according to the method of Fischer and Phäler. ${ }^{7}$

Preparative specifications. The acetal isomers were separated on a preparative gas chromatographic column, $5^{\prime} \times 1 / 4^{\prime \prime}$, containing $20 \%$ Carbowax $20 \mathrm{M}$ on $60 / 80$ mesh

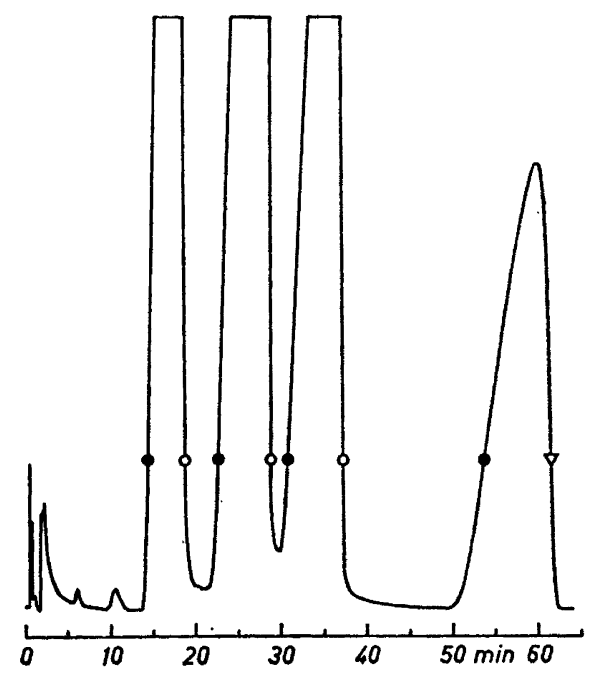

Fig. 1. Preparative chromatogram of glycerol acetal isomers (cf. experimental part).

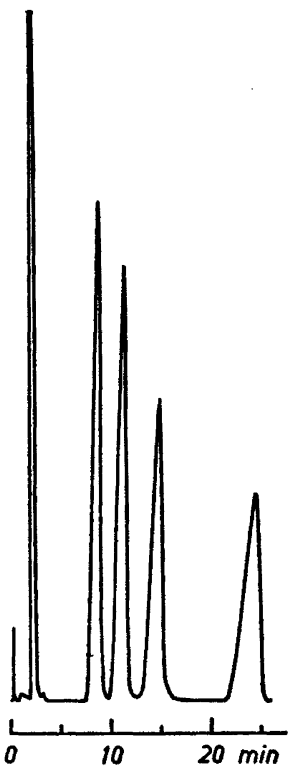

Fig. 2. Analytical chromatogram of glycerol acetal isomers (cf. experimental part).

Acta Chem. Scand. 19 (1965) No. 4 
firebrick. An automatic instrument, Aerograph Autoprep A-700, was used. Column temperature: $146^{\circ} \mathrm{C}$. Helium flow: $40 \mathrm{ml} / \mathrm{min}$. Injection temperature: $220^{\circ} \mathrm{C}$. Sample size: $200 \mu$ l. Time of analysis: $60 \mathrm{~min}$. A typical preparative chromatogram is recorded in Fig. 1. The circles on the peaks show where the collection of the various fractions have been started and stopped during the preparation.

Analytical specifications. For analytical separation was used a $5^{\prime} \times 1 / 8^{\prime \prime}$ column filled with $20 \%$ PDEAS on $60 / 80$ mesh firebrick. Column temperature: $110-120^{\circ} \mathrm{C}$. Helium flow: $40 \mathrm{ml} / \mathrm{min}$. The Honeywell-Brown recorder was fitted with Disc chart integrator. A typical chromatogram is shown in Fig. 2.

The infrared spectra of the compounds were recorded on a Unicam S.P. 100, MK 2 instrument fitted with sodium chloride prism as well as grating optics. In the region of the hydroxyl absorption the spectra were recorded in carbon tetrachloride, in other regions as films.

Rate and equilibrium measurements were performed in thermostated glass tubes of $0.4 \mathrm{ml}$ capacities, sealed with silicone rubber gaskets through which a syringe needle could be stung. After fixed time intervals, samples were drawn into the syringe and neutralised with a large excess of pyridine. Thereafter, the sample was applied to the analytical column.

\section{ASSIGNMENT OF CONFIGURATIONS TO THE VARIOUS ISOMERS}

The infrared bands of the four cyclic acetal isomers separated on the gas chromatographic column are recorded in Table 1. Isomers (B) and (C) have many absorption bands at the same or almost the same wave numbers; this is especially true for the $\mathrm{O}-\mathrm{H}$ and $\mathrm{C}-\mathrm{H}$ vibrations. It is reasonable to assume that (B) and (C) constitute a cis-trans pair of the same cyclic form, either the 1,3-dioxolane or the 1,3-dioxane ring. By corresponding arguments, isomers (A) and (D) probably constitute the other cis-trans pair. Convincing evidence that the cis-trans pair (B) and (C) are the five-membered 1,3-dioxolanes $(\mathrm{I})$, comes from a comparison of their $\mathrm{O}-\mathrm{H}$ and $\mathrm{C}-\mathrm{H}$ bands with the corresponding infrared bands of the cyclic ketal, 4-hydroxymethyl-2-dimethyl1,3-dioxolane, obtained from acetone and glycerol. This reaction is reported ${ }^{13}$ to give the five-membered 1,3-dioxolane derivative exclusively, which we have confirmed by gas chromatographic analysis. The cyclic ketal has a primary hydroxyl group which absorbs in infrared at 3635 and $3597 \mathrm{~cm}^{-1}$, corresponding to the free and intramolecularly bonded $\mathrm{O}-\mathrm{H}$ group, respectively. The corresponding bands of the isomers $(\mathrm{B})$ and $(\mathrm{C})$ absorb at exactly the same wave numbers (Table 1); this strongly indicates the 1,3-dioxolane structure. Likewise, the $\mathrm{C}-\mathrm{H}$ peaks of the cyclic ketal at 2888,2940 , and $2990 \mathrm{~cm}^{-1}$ correspond nicely with the same bands of isomers (B) and (C).

The free hydroxyl band of isomer (D) at $3624 \mathrm{~cm}^{-1}$ is $11 \mathrm{~cm}^{-1}$ lower than the bands of the free primary hydroxyl groups of $(B)$ and $(C)$. Since secondary hydroxyl groups are known to absorb approximately $10 \mathrm{~cm}^{-1}$ lower than primary ones, this finding indicates that isomer (D) belongs to the 1,3-dioxane pair (II).

The assignment of cis and trans configuration to the 1,3-dioxanes (A) and (D), respectively, is based on the following observations:

1. Barker et al. ${ }^{8}$ have found that the $c i s$ isomers of various 5-hydroxy-2-X1,3-dioxanes, where $X$ represents different substituents, have intramolecularly hydrogen-bonded hydroxyl groups exclusively. Isomer (A) of the 1,3-dioxane pair, shows a hydrogen-bonded hydroxyl group only, thus indicating the cis form. 
Table 1. Infrared bands $\left(\mathrm{cm}^{-1}\right)$ of the isomers of glycerol acetal.

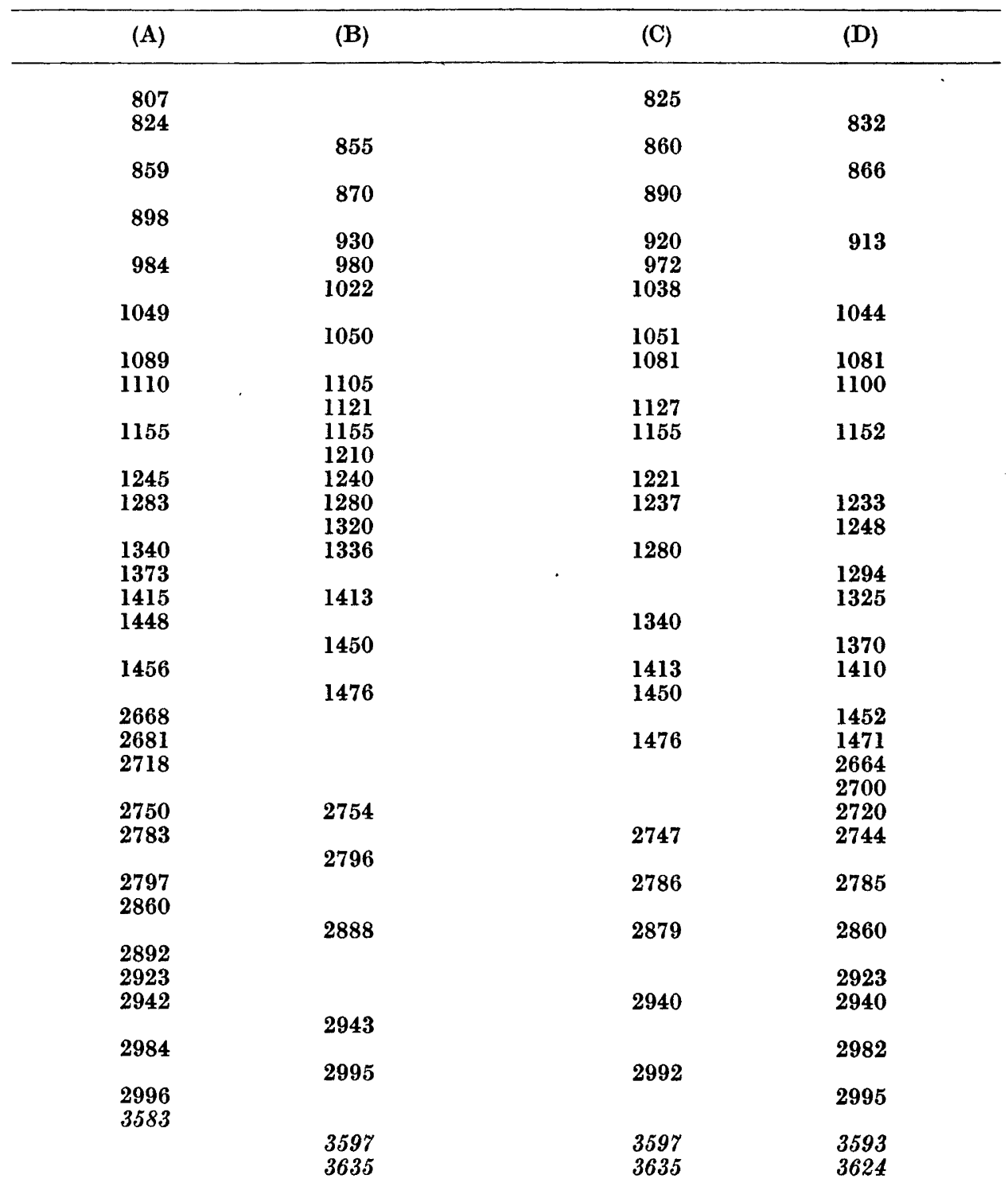

2. The modified Auwers-Skita rule ${ }^{10-12}$ states that cis isomers of 1,4disubstituted cyclohexanes have always the highest refractive indexes and the highest densities. The 1,3-dioxane isomers (A) and (D) most probably are in the chair forms, characteristic for cyclohexane derivatives, and would therefore be expected to obey the Auwers-Skita rule. The data recorded in Table 2, accordingly indicate compound (A) to be the cis isomer.

Acta Chem. Scand. 19 (1965) No. 4 


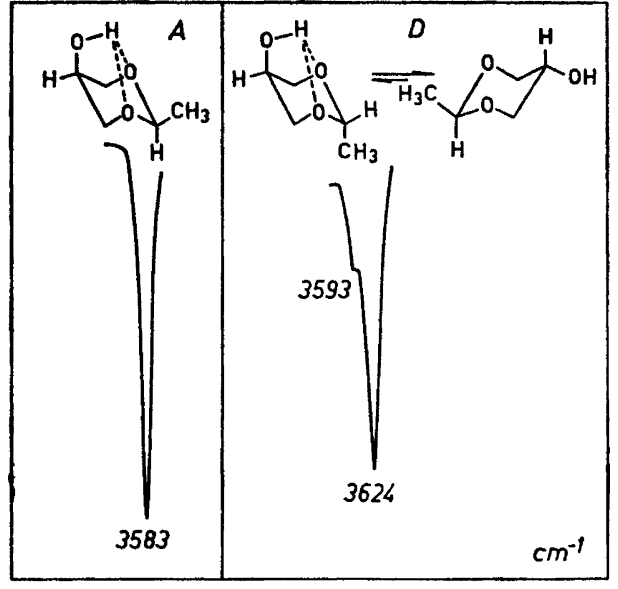

Fig. 3. Free and associated $\mathrm{OH}$-bands of glycerol acetal isomers $\mathrm{A}$ and $\mathrm{D}$ in $\mathrm{CCl}_{4}$.

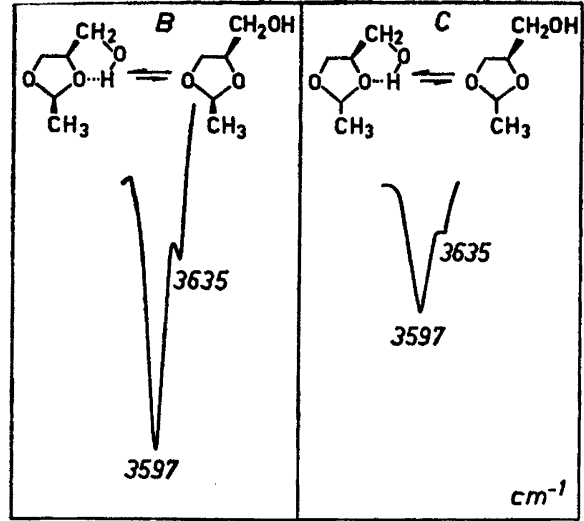

Fig. 4. Free and associated $\mathrm{OH}$-bands of glycerol acetal isomers $\mathrm{B}$ and $\mathrm{C}$ in $\mathrm{CCl}_{4}$.

3. Usually, the retention times of polar compounds on chromatographic columns are shortest for cis isomers. Isomers (A) and (D) have retention times of 9 and $24.5 \mathrm{~min}$, respectively, again indicating (A) to be the cis isomer (Table 2).

Judging from the ratio between the intensities of free and associated hydroxyl bands (Figs. 3 and 4) and from the displacement, $\Delta v_{\mathrm{OH}}$, of the hydroxyl peak (Table 2), the degree of internal saturation of the isomers through hydrogen bonding decreases from (A) to (D). It is interesting to note that the retention times increase in the same order (Table 2). The reason is most probably that an increase of the internal saturation results in a corresponding decrease of intermolecular forces between the acetals and the liquid phase of the column.

Essentially the same arguments as above, can be used to assign the cis and trans configurations to the 1,3-dioxolane isomers (B) and (C), respectively. Barker $e t a l .^{9}$ from studies of the infrared spectra of $c i s$ and trans isomers of 2,4-dimethyl-1,3-dioxolane, found strong absorption bands in the region $1040-920 \mathrm{~cm}^{-1}$, which they believed to be due to skeletal vibrations of the

Table 2. Physical data of the isomers of glycerol acetal.

\begin{tabular}{cccccc}
\hline Isomer & $\begin{array}{c}\text { Refractive } \\
\text { index } \\
n_{\mathrm{D}}{ }^{20}\end{array}$ & $\begin{array}{c}\text { Density } \\
d_{\mathbf{4}}{ }^{19}\end{array}$ & $\begin{array}{c}\Delta v_{\mathrm{OH}} \\
\mathrm{cm}^{-1}\end{array}$ & $\begin{array}{c}\text { Retention } \\
\text { time (min) } \\
119^{\circ} \mathrm{C}\end{array}$ & $\begin{array}{c}\text { Rate of isomerisa- } \\
\text { tion in benzene } \\
\text { (first order rate } \\
\text { constant, } \text { sec }^{-1} \text { ) }\end{array}$ \\
\hline A & 1.4487 & 1.152 & 41 & 9 & $0.87 \times 10^{-5}$ \\
B & 1.4363 & 1.130 & 38 & 11.5 & $1.11 \times 10^{-5}$ \\
C & 1.4380 & 1.124 & 38 & 14.5 & $1.01 \times 10^{-5}$ \\
D & 1.4424 & 1.138 & 31 & 24.5 & $2.38 \times 10^{-5}$
\end{tabular}

a Catalyst: $5.6 \times 10^{-7} \mathrm{~mole} / 1 \mathrm{HClO}_{4}, 70^{\circ} \mathrm{C}$. 


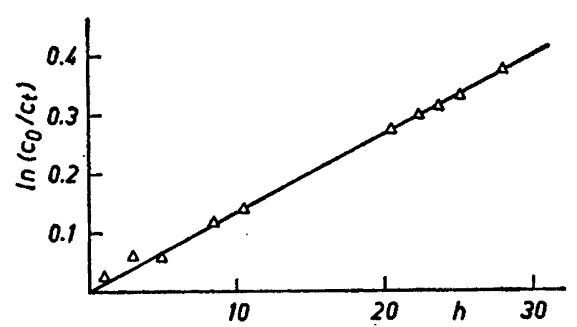

Fig. 5. First order plot of the rate of isomerisation of the pure trans isomer of 4-hydroxymethyl-2-methyl-1,3-dioxolane without added catalyst. Temp $79.3^{\circ} \mathrm{C}$.

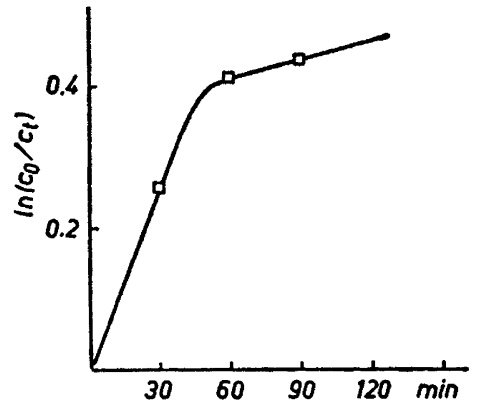

Fig. 6. Rate of isomerisation of the pure trans isomer of 4-hydroxymethyl-2. methyl-1,3-dioxolane in the presence of approximately $10^{-8}$ mole/l hydrochloric acid. Temp. $75^{\circ} \mathrm{C}$.

ring. The strongest peaks of the cis isomer were located at 1022, 947, and 935 $\mathrm{cm}^{-1}$, whereas the trans isomer absorbed at 1036,943 , and $926 \mathrm{~cm}^{-1}$. Isomers (B) and (C) have peaks (Table 1) at 1022, 980,930 $\mathrm{cm}^{-1}$, and at 1038, 972, 920 $\mathrm{cm}^{-1}$, respectively, indicating (B) to be the cis isomer.

Likewise, the retention times in Table 2 point to isomer $(\mathrm{B})$ as the cis compound.

\section{RATES OF ISOMERISATION OF THE ACETAL ISOMERS}

The isomerisation of the acetal isomers is well suited for gas chromatographic analysis, because the isomerisation, which is acid catalysed, can be effectively stopped by addition of base. The isomerisation is extremely sensitive towards acids. In fact, the acidity of the glass wall of the reaction vessel is sufficient to promote the isomerisation of the most labile isomers.

When the reactions are studied within the first $20 \%$ of isomerisation the kinetics are strictly first order. In Fig. 5 is shown first order plot of the pure trans isomer of 4-hydroxymethyl-2-methyl-1,3-dioxolane (I) without added catalyst.

The sensitivity of the pure isomers towards acids is so great that rate studies are not practicable with acid concentrations higher than approximately $10^{-8} \mathrm{M}$. Experiments have shown that the rate of acid catalysed isomerisation of the pure isomers is far from proportional to the acid concentration. There appears to be a threshold concentration, below which the rate is equal to that of the uncatalysed isomerisation. Above this threshold, the concentration region within which measureable rates can be obtained is very restricted. It might be argued that the catalytic amounts of hydrochloric acid present could react with the acetal to give an open-chain product:

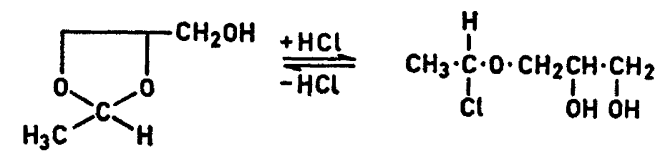

Acta Chem. Scand. 19 (1965) No. 4 


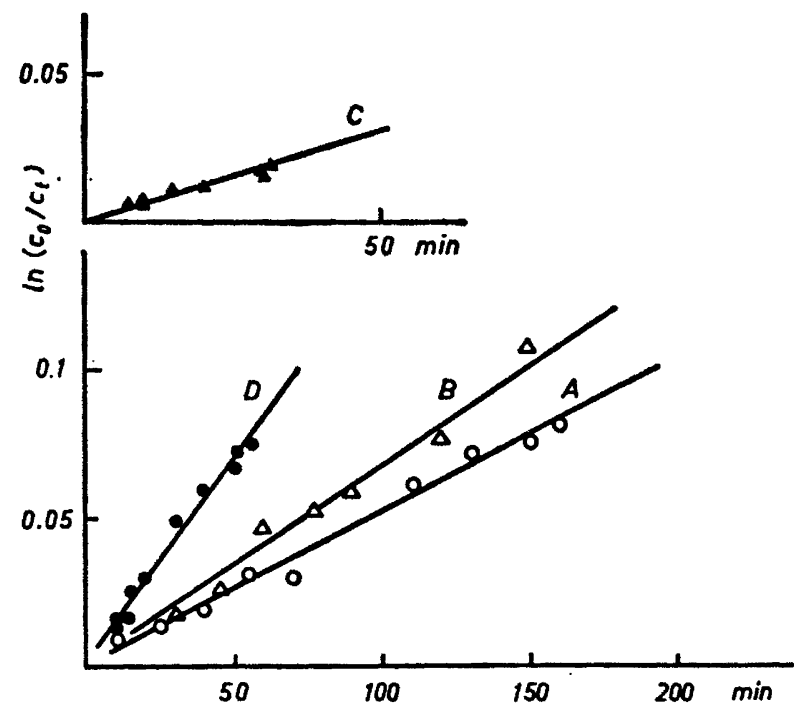

Fig. 7. First order plots of the rate of isomerization of glycerol acetal isomers (A), (B), (C), and (D) in benzene solution. Catalyst: $5.6 \times 10^{-7}$ mole/ $1 \mathrm{HClO}_{4}$. Temp. $70.0^{\circ} \mathrm{C}$.

This assumption is doubtful, however, since it was found that perchloric acid gave essentially the same reaction picture. Another characteristic feature of the acid catalysed isomerisation of the pure compounds is a very sudden drop in rate after a short time of reaction (Fig. 6). The rate decrease is too abrupt to be caused by the backward reactions of the formed isomers, and points to a destruction of the acid catalyst in some way.

In benzene solution the acid catalysed isomerisation is much easier to control since the concentrations of acetal and acid can be varied at will. Some representative experiments are plotted in Fig. 7. It is interesting to observe that the rate of isomerisation increases with decreasing internal hydrogen bonding in the acetals (compare the rate data with $\Delta v_{\mathrm{OH}}$ in Table 2. See also Figs. 3 and 4). Since isomerisation of acetals exhibits specific acid catalysis, it is reasonable that the strongest internally hydrogen bonded isomer is less sensitive to attack from an external proton.

Table 3. Equilibrium constants and thermodynamic data for the 1,3-dioxolane/1,3-dioxane system of glycerol acetal.

\begin{tabular}{|c|c|c|c|c|}
\hline$\underset{{ }^{\circ} \mathbf{C}}{\text { Temp. }}$ & $k$ & $\underset{\mathrm{cal} / \mathrm{mole}}{\Delta F^{\prime}}$ & $\begin{array}{c}\Delta S \\
\text { cal/deg. mole }\end{array}$ & $\underset{\mathrm{kcal} / \mathrm{mole}}{\Delta H \text { (average) }}$ \\
\hline $\begin{array}{c}70 \\
75 \\
80 \\
106.5\end{array}$ & $\begin{array}{l}0.8913 \\
1.005 \\
1.195 \\
2.371\end{array}$ & $\begin{array}{r}77.7 \\
9.86 \\
-135 \\
-650\end{array}$ & $\begin{array}{l}-20.2 \\
-20.1 \\
-20.3 \\
-20.2\end{array}$ & $-7.00 \pm 0.5$ \\
\hline
\end{tabular}

Acta Chem. Scand. 19 (1965) No. 4 


\section{EQUILIBRIUM STUDIES OF THE ACETAL ISOMERS}

The equilibrium between the four acetal isomers was studied by acid catalysed isomerisation of one of the pure isomers. The same equilibrium ratio was established whether the dioxane or the dioxolane derivatives were used as starting material. The results from measurements at four different temperatures are recorded in Table 3. In Fig. 8 are plotted $\ln K$ against $1 / T$, from which the enthalpy difference, $\Delta H$, between the pair of the five-membered 1,3-dioxolane isomers and the pair of the six membered 1,3-dioxane isomers is calculated as $-7.0 \pm 0.5 \mathrm{kcal}$, the latter pair being the most stable.

The 20 e.u. lower entropy of the dioxanes as compared with the dioxolanes is perhaps the most interesting result. The dioxolane isomers have a methylol group attached to the ring, whereas the dioxane isomers contain a hydroxyl group; this gives rise to a greater flexibility of the dioxolane isomers. The dioxane isomers are also to a larger degree intramolecularly hydrogen bonded which further increases the rigidity of the molecules and contributes to a loss of entropy (Figs. 3 and 4). The low frequency of the $e a \rightleftharpoons a e$ transition of the cis form, and of the $e e \rightleftharpoons a a$ transition of the trans form of the 1,3-dioxanes, as compared with the corresponding "pseudorotation" of the 1,3-dioxolanes, may also contribute to an unfavourable entropy of the dioxanes.

The equilibrium experiments (Table 3) clearly show that the yield of the various acetal isomers is strongly temperature dependent, lower temperatures favouring the 1,3-dioxane system. Studies of the product composition during the first minutes of synthesis, of the acetal from glycerol and acetaldehyde, show that the 1,3-dioxolane isomers are most quickly formed, but that the

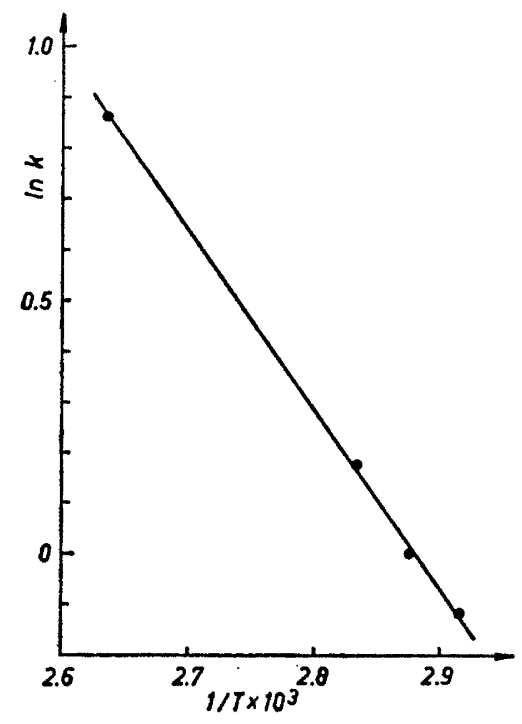

Fig. 8. The plot of $\ln K$ against $1 / T$ for the equilibrium 1,3-dioxolane/1,3-dioxane forms of glycerol acetal isomers.

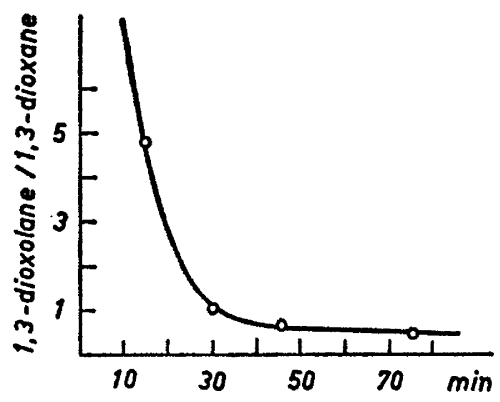

Fig. 9. The plot of the ratio 1,3-dioxolane/ 1,3-dioxane isomers at different times after start of synthesis. Reaction temp. $25^{\circ} \mathrm{C}$.

Acta Chem. Scand. 19 (1965) No. 4 
<smiles>CC1(C)OC2COC(CO)(O2)O1</smiles>

(III).<smiles>CC1(C)OCC(O)CO1</smiles>

(II)

reaction mixture proceeds towards equilibrium very rapidly (Fig. 9). The easier formation of the dioxolane system is most likely due to a higher frequency factor for the closing of the five-membered ring as compared with the sixmembered one.

ISOLATION OF THE SIX-MEMBERED CYCLIC KETAL, 5-HYDROXY.2,2DIMETHYL-1,3-DIOXANE

As mentioned earlier, acetone and glycerol give only the five-membered dioxolane derivatives (III) under ordinary synthetic conditions.

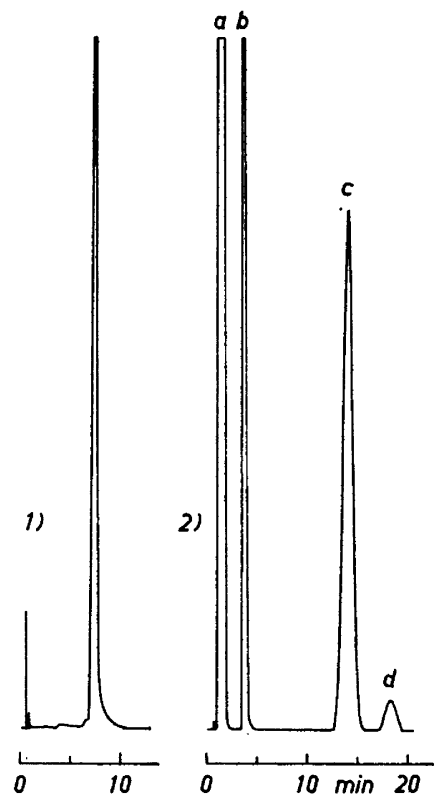

Fig. 10. 1) Chromatogram of 4-hydroxymethyl-2,2-dimethyl-1,3-dioxolane.

2) Chromatogram after isomerisation of the dioxolane isomer at $-4^{\circ} \mathrm{C}$ for 4 days in the presence of hydrochloric acid: a) benzene, b) pyridine, c) 4-hydroxy. methyl-2,2-dimethyl-1,3-dioxolane,

d) 5-hydroxy-2,2-dimethyl-1,3-dioxane.

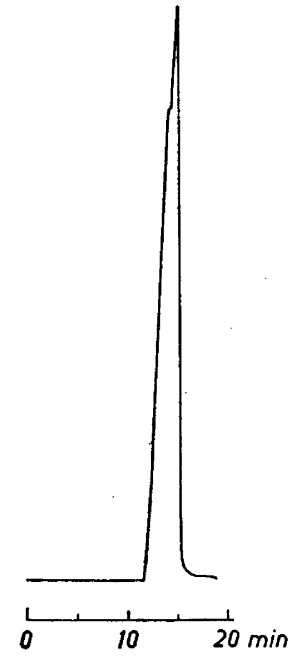

Fig. 11. Chromatogram of glycerol formal.

Acta Chem. Scand. 19 (1965) No. 4 
On the basis of the enthalpy and entropy values found for the dioxolane/ dioxane systems of the acetal isomers, an attempt was made to estimate the equilibrium constant of the dioxolane/dioxane systems of the corresponding ketal isomers (III) and (IV).

According to the hypothesis mentioned in the introduction of the present paper, the instability of the 1,3-dioxane ring of the ketal is due to an axial opposition of the 2-methyl group and the hydrogen atoms in the 4- and 6positions in the ring. As a first approximation we assume that the axial repulsion energy is equal to the corresponding repulsion energy in methyl cyclohexane, which is of the magnitude of $2 \mathrm{kcal} .{ }^{16}$ If, further, the entropy difference in the dioxolane/dioxane system of the ketals is set equal to that of the acetals, the equilibrium constant of the ketal system is calculated to be 0.14 at $0^{\circ} \mathrm{C}$. Thus, according to this crude estimate it should be possible to isolate the sixmembered cyclic ketal from the five-membered ketal by isomerisation at sufficiently low temperature. This was experimentally confirmed through isolation of a two percent yield of the 1,3-dioxane-isomer of the ketal after keeping a sample of the pure 1,3-dioxolane isomer with acid catalyst below $0^{\circ} \mathrm{C}$ for several days (Fig. 10). Due to the very low rate of isomerisation, the approach towards equilibrium was extremely slow so that it was not attempted to measure the equilibrium ratio. Infrared analysis showed that the new isomer had a free hydroxyl peak at $3625 \mathrm{~cm}^{-1}$, i.e. $10 \mathrm{~cm}^{-1}$ lower than the $1,3-$ dioxolane compound, which clearly demonstrates the presence of a secondary hydroxyl group characteristic of the 1,3-dioxane ring. As mentioned earlier, exactly the same behaviour was observed for the acetal isomers (Table 1).

Brimacombe et al. ${ }^{14}$ have reported that the isomers of glycerol formal cannot be separated gas chromatographically. Experiments performed by us with various column materials have resulted in a partial separation sufficient to show that the isomers are present in comparable amounts (Fig. 11). This result confirms earlier findings of Hibbert and Carter ${ }^{15}$ who isolated the isomers via the benzoates. With regard to the ratio between dioxolane and dioxane isomers, the formal system thus resembles the acetal system but differs from that of the ketal which at the same temperature exists only in the dioxolane form. Due to the absence of substituents in the 2-position of the dioxane form of the formal, no axial repulsion with the 4- and 6-hydrogen atoms of the ring is expected, and the observed resemblance with the acetal is therefore reasonable.

\section{REFERENCES}

1. Harnitzky, T. and Menschutkin, N. Ann. 136 (1865) 126.

2. Nef, J. U. Ann. 335 (1904) 216.

3. Hill, H. S. and Hibbert, H. J. Am. Chem. Soc. 45 (1923) 3117.

4. Hill, H. S., Hill, A. C. and Hibbert, H. J. Am. Chem. Soc. 50 (1928) 2242.

5. Triggle, D. J. and Belleau, B. Can. J. Chem. 40 (1962) 1201.

6. Eliel, E. L. Stereochemistry of Carbon Compounds, McGraw Hill Book Company, New York 1962, p. 200.

7. Fischer, E. and Phäler, E. Ber. 53 (1920) 1607.

8. Barker, S. A., Brimacombe, J. S., Foster, A. B., Whiffen, D. H. and Zweifel, G. Tetrahedron 7 (1959) 10. 
9. Barker, S. A., Boume, E. J., Pinchard, R. M. and Whiffen, D. H. J. Chem. Soc. 1959807.

10. Auwers, K. v. Ann. 420 (1920) 84.

11. Skita, A. Ber. 56 (1923) 1014.

12. Ref. 6, p. 216.

13. Irvine, J. C., MacDonald, J. L. A. and Soutar, C. W. J. Chem. Soc. 107 (1915) 337.

14. Brimacombe, J. S., Foster, A. B. and Haines, A. H. J. Chem. Soc. 19602582.

15. Hibbert, H. and Carter, N. M. J. Am. Chem. Soc. 50 (1928) 3120.

16. Ref. 6, p. 204.

Received February 12, 1965. 